\title{
CONVERSION OF THE PS COMPLEX AS LHC PROTON PRE-INJECTOR
}

\author{
F. Blas, R. Cappi, V. Chohan, D. Cornuet, G. Daems, D. Dekkers, R. Garoby, D. Grier, J. Gruber, \\ E. Jensen, H. Koziol, A. Krusche, K.D. Metzmacher, F. Pedersen, J. Pedersen, U. Raich, \\ J.P. Riunaud, J.P. Royer, M. Sassowsky, K. Schindl, H. Schönauer, M. Thivent, H. Ullrich, \\ F.Völker, CERN, 1211 Geneva 23, Switzerland
}

\section{Abstract}

CERN's Large Hadron Collider (LHC) [1][2] will be supplied with protons from the injector chain Linac2-PS Booster (PSB)-PS-SPS (Fig. 1). The required transverse beam brilliance (intensity/emittance) is almost twice that of current PS beams and the LHC bunch spacing of $25 \mathrm{~ns}$ must be impressed on the beam before its transfer to the SPS. The scheme involves new RF harmonics in the PSB and the PS, an increase of the PSB energy, and two-batch filling of the PS. After a successful test of the main ingredients, a project for converting the PS complex was launched in 1994. Major additions are (i) $h=1 \mathrm{RF}$ systems in the PSB, (ii) upgrading of the PSB main magnet supply from 1 to $1.4 \mathrm{GeV}$ operation, (iii) new magnets, septa, power supplies, kicker pulsers for the PSB-PS beam transfer, (iv) 40 and $80 \mathrm{MHz}$ systems in the PS, (v) beam profile measurement devices with improved resolution. A significant part of the effort is being provided by TRIUMF under the Canada-CERN co-operation agreement on the LHC.

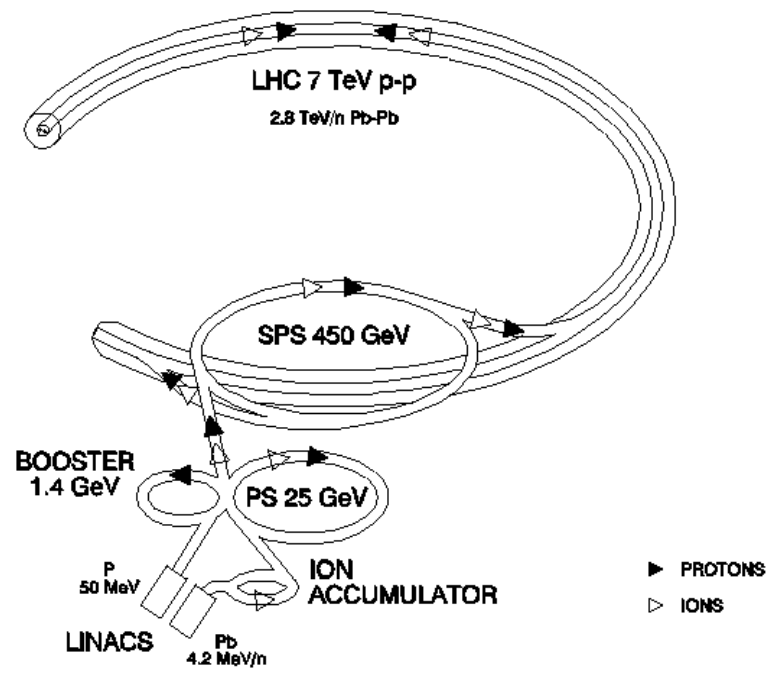

Fig. 1: The LHC injector complex.

\section{LHC REQUIREMENTS}

Supplying the LHC with protons from the existing chain of injectors may appear straightforward at first sight. However, the beam has to fit into the tiny LHC dynamic aperture, and must also have the brilliance required for
LHC's desired luminosity. While the intensity is well within the capabilities of the PS complex (Linac2, PSB, PS), the beam brilliance requested (here defined as intensity per bunch/normalised rms emittance) needs to be up to twice that of current beams. LHC proton beam parameters at collision ( $7 \mathrm{TeV}$ per beam) at various stages of operation are summarised in Table 1.

\begin{tabular}{|l|c|c|c|}
\cline { 2 - 4 } \multicolumn{1}{c|}{} & $\begin{array}{c}\text { Commis- } \\
\text { sioning }\end{array}$ & $\begin{array}{c}\text { Nomi- } \\
\text { nal }\end{array}$ & $\begin{array}{c}\text { beam-beam } \\
\text { limit }\end{array}$ \\
\hline Luminos. $\left[\mathrm{cm}^{-2} \mathrm{~s}^{-1}\right]$ & $10^{33}$ & $10^{34}$ & $2.510^{34}$ \\
\hline bunch spacing $[\mathrm{ns}]$ & \multicolumn{3}{|c|}{25} \\
\hline bunches/beam & \multicolumn{3}{|c|}{2835} \\
\hline protons/bunch & $1.710^{10}$ & $10^{11}$ & $1.710^{11}$ \\
\hline$\varepsilon *\left(=\beta \gamma \sigma^{2} / \beta_{\mathrm{x}, \mathrm{y}}\right)[\mu \mathrm{m}]$ & 1.0 & 3.75 & 3.75 \\
\hline
\end{tabular}

Table 1: LHC proton beam parameters at collision. Note that $\varepsilon^{*}=\varepsilon_{\mathrm{x}} *=\varepsilon_{\mathrm{y}}{ }^{*}$.

The injector chain has to produce beams corresponding to the nominal performance; wherever possible, a higher performance level is aimed at, to potentially fill the LHC up to the beam-beam limit and to provide an operational margin.

\section{A SCHEME TO REDUCE SPACE CHARGE}

With a beam brilliance corresponding to the LHC beambeam limit, the space-charge tune shifts $(\Delta Q)$ are almost twice the present figures at the PSB $(50 \mathrm{MeV})$ and PS $(1 \mathrm{GeV})$ injection energies, leading to unacceptable beam blow-up and loss.

\subsection{Double-batch filling of the PS to reduce space charge in the PSB}

Usually the four PSB rings (each $1 / 4$ of PS circumference) are transferred sequentially (3-4-2-1), to fill the PS in one pulse. The LHC beam would generate, at PSB injection, a $\Delta Q=0.9$, far beyond the "hard" limit of 0.55. With two PSB pulses to fill the PS, the intensity per PSB pulse is halved and $\Delta Q$ reduced to 0.45

\subsection{RF harmonic 1 in PSB for two-batch filling of the PS}

With the RF equal to the PSB revolution frequency, there is just one bunch per ring (5 at present) and two-batch filling of the PS becomes feasible. Appropriate phasing of the bunch in each ring before extraction enables the four 
bunches to be lodged in $1 / 2$ of the PS (Fig. 2), which can then accommodate a second batch.

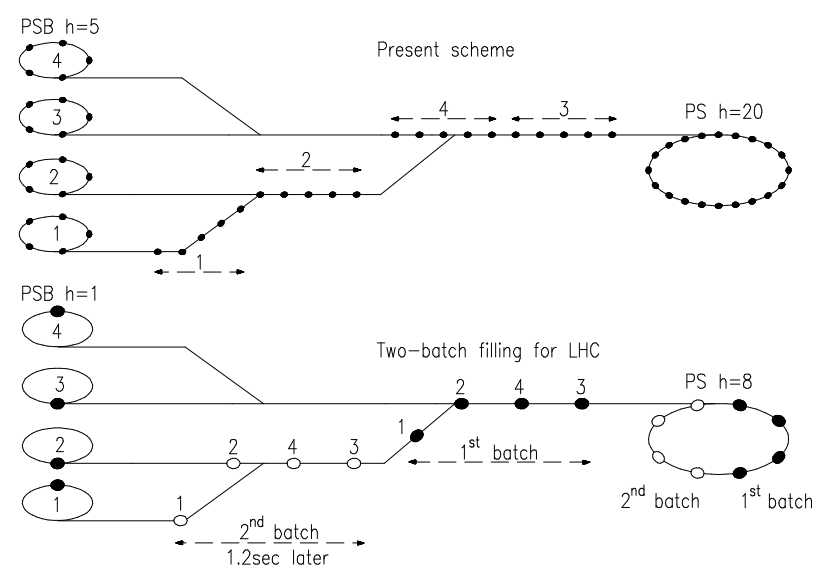

Fig. 2: PSB-PS four-ring transfer schemes.

\subsection{PSB energy to $1.4 \mathrm{GeV}$ to reduce tune spread in PS}

The first batch from the PSB dwells for $1.2 \mathrm{sec}$ on the PS injection plateau until the second batch arrives and is particularly vulnerable to a large $\Delta Q$. The increase of the PSB energy will reduce the tune shift from 0.3 to a more comfortable 0.2 .

For convenience, the main machine parameters of the LHC injector chain (including the SPS [3]) are compiled in Table 2. Note that the RF harmonic number 84 in the PS corresponds to the LHC bunch spacing of $25 \mathrm{~ns}$ which is impressed on the beam in the PS on the $25 \mathrm{GeV}$ extraction flat top.

\begin{tabular}{|l|c|c|c|}
\cline { 2 - 4 } \multicolumn{1}{c|}{} & PSB & PS & SPS \\
\hline kinetic energy [GeV] & 1.4 & 25 & 450 \\
\hline repetition time [s] & 1.2 & 3.6 & 16.8 \\
\hline $\begin{array}{l}\text { number of pulses to fill } \\
\text { downstream machine }\end{array}$ & 2 & 3 & $2 \times 12$ \\
\hline number of bunches & $1 /$ ring & $8(16) / 84$ & 243 \\
\hline p/pulse nominal $\left[10^{11}\right]$ & 43 & 84 & 240 \\
beam-beam & 72 & 140 & 405 \\
\hline p/bunch nominal $\left[10^{11}\right]$ & 11 & $10.5 / 1.0$ & 1.0 \\
beam-beam & 18 & $17.5 / 1.7$ & 1.7 \\
\hline emittance $\varepsilon^{*}[\mu \mathrm{m}]$ & 2.5 & 3.0 & 3.5 \\
\hline
\end{tabular}

Table 2: The LHC proton injector chain.

\section{MAJOR HARDWARE UPGRADES}

The $50 \mathrm{MeV}$ proton linac is now equipped with a $750 \mathrm{keV}$ RFQ and produces a beam of unprecedented brightness: $150 \mathrm{~mA}$ in $\varepsilon^{*}=1.2 \mu \mathrm{m}$ during $120 \mu \mathrm{s}$. Ways to increase this intensity to $180 \mathrm{~mA}$ (albeit during only $20 \mu$ s) are under study.

\subsection{New RF systems in PSB}

New $h=1$ ferrite-filled RF cavities with a frequency swing of 0.6 to $1.7 \mathrm{MHz}, 8 \mathrm{kV}$, will accelerate one bunch in each ring. Moreover, the present $h=5$ cavities will be modified for a tuning range of 1.2 to $3.9 \mathrm{MHz}(h=2)$ to flatten the bunches and thus reduce the space charge $Q$ shift in the low-energy part of the cycle.

\subsection{Upgrading the PSB to $1.4 \mathrm{GeV}$}

Raising the PSB output energy from 1 to $1.4 \mathrm{GeV}$ implies an increase of the main dipole field by $26 \%$ to $0.87 \mathrm{~T}$ and of the quadrupole gradient to $\sim 5 \mathrm{~T} / \mathrm{m}$. Beam measurements at these field levels have shown no sign of saturation. However, the main power supply needs upgrading: putting into service a fourth rectifier-inverter group, renewal of $18 \mathrm{kV}$ transformers, including the reactive power compensation system, and implementing new controls circuitry.

\subsection{PSB-PS beam transport to $1.4 \mathrm{GeV}$}

The bending power of most of the magnetic elements of this line cannot be increased by $26 \%$. Eight dc septum magnets are to be replaced by pulsed ones, three vertical bending magnets, six quadrupoles, and a series of correction dipoles are to be rebuilt with laminated yokes [4] and equipped with new power converters. This will permit the change of beam energy from pulse to pulse. The eight kicker magnets are being refurbished with more powerful pulsers [5].

\subsection{Acceleration on new RF harmonics in the PS}

The PS RF cavities are tuned to $h=8$ so as to accommodate the 8 PSB bunches (Fig. 2). These are then accelerated to $3.5 \mathrm{GeV} / \mathrm{c}$ where they are split to 16 bunches, followed by acceleration on $h=16$. New lowlevel electronics to cope with these harmonics is being built.

\subsection{0 and $80 \mathrm{MHz} R F$ systems in the PS [6]}

The LHC bunch spacing of $25 \mathrm{~ns}$ as well as bunch length matching $(<4 \mathrm{~ns})$ to the SPS are obtained with fixedfrequency RF systems. A $40 \mathrm{MHz}$ cavity $(300 \mathrm{kV})$ bunches the beam on $h=84$, whereas two $80 \mathrm{MHz}$ systems $(600 \mathrm{kV})$ are added to shorten the bunches, to fit into the SPS $200 \mathrm{MHz}$ buckets. The design features a sophisticated mechanical short-circuit, as well as a powerful feedback to prevent high-intensity beams from suffering beam loading effects.

\subsection{Beam diagnostics}

Several systems are to be improved owing to the small size of the LHC beam, the new RF harmonics, and the intricacies of two-batch filling. Of particular relevance is the resolution of beam profile measurement devices (SEM grids, fast wire scanners) which must be increased by more than a factor 2 .

\section{BEAM TESTS - PAST AND FUTURE}

\subsection{Major results obtained so far}

A partial test to check the proposed LHC proton filling scheme in the PS complex was carried out in late 
1993 [7]. Only PSB ring 3 was used; its hardware was adapted by means of prototypes and pushing some elements beyond their safe limits. It has demonstrated that a proton beam can be produced at $25 \mathrm{GeV}$ that meets the LHC specifications in terms of intensity and $\varepsilon^{*}$ and confirmed the main ingredients of the scheme. More recently, the newly installed $40 \mathrm{MHz}$ cavity was successfully used to bunch the beam with $25 \mathrm{~ns}$ spacing; the fast feedback system lowers the cavity impedance sufficiently to prevent high-intensity beams from becoming unstable.

\subsection{Main beam dynamics issues [8][9]}

The last line in Table 2 highlights the tight emittance budget available in the injector chain; every effort has to be made to avoid transverse blow-up. While space-charge detuning sweeps the beam over stop-bands and leads to an unavoidable emittance increase in the synchrotrons, emittance can be conserved in beam transport systems: mis-steering is to be minimized by automatic procedures, and corrected with fast dampers; mismatch is to be tackled by on-line quadrupole correction [10].

The new RF systems and harmonics will need intensive study [11]: (i) keeping the PSB $h=2 \mathrm{RF}$ in step with the $h=1 \mathrm{RF}$ even at highest intensity; (ii) bunch splitting from 8 to 16 in the PS; (iii) techniques to depopulate the bunch centre (for lowering space charge); (iv) RF gymnastics in the debunching/recapture process (from $h=16$ to $h=84$ ) at $25 \mathrm{GeV}$.

Another issue is to make sure that the proposed modifications do not jeopardize the beams for other users.

\begin{tabular}{|l|l|l|}
\hline ITEM & STATUS & TRIUMF PART \\
\hline $\begin{array}{l}\text { PSB } h=1 \mathrm{RF} \\
\text { systems (4) }\end{array}$ & $\begin{array}{l}\text { prototype in one } \\
\text { ring }\end{array}$ & $\begin{array}{l}\text { ferrites } \\
\text { power supplies }\end{array}$ \\
\hline $\begin{array}{l}\text { PSB } h=2 \mathrm{RF} \\
\text { systems (4) }\end{array}$ & $\begin{array}{l}\text { one cavity com- } \\
\text { mutable } h=5 / h=2\end{array}$ & \\
\hline PSB main supply & $\begin{array}{l}\text { control circuitry } \\
\text { being tested }\end{array}$ & $\begin{array}{l}\text { transformers (10) } \\
\text { var compensator }\end{array}$ \\
\hline $\begin{array}{l}\text { PSB-PS kicker } \\
\text { pulsers (7) }\end{array}$ & prototype tests & $\begin{array}{l}\text { study on pulse- } \\
\text { flattening [5] }\end{array}$ \\
\hline $\begin{array}{l}\text { PSB-PS septa (8) } \\
\text { and supplies }\end{array}$ & two are operational & \\
\hline $\begin{array}{l}\text { PSB-PS line } \\
\text { magnets (14) and } \\
\text { power supplies }\end{array}$ & $\begin{array}{l}\text { magnets: } 1 / 2 \text { are } \\
\text { ready; supplies: } \\
\text { prototype tested }\end{array}$ & $\begin{array}{l}\text { all magnets [4], } \\
\text { all power supplies }\end{array}$ \\
\cline { 1 - 2 } $\begin{array}{l}\text { PS } 40 \mathrm{MHz} \\
\text { cavities (2) }\end{array}$ & $\begin{array}{l}\text { one cavity } \\
\text { operational }\end{array}$ & $\begin{array}{l}\text { model studies, } \\
\text { tuners, }\end{array}$ \\
\cline { 1 - 2 } $\begin{array}{l}\text { PS } 80 \mathrm{MHz} \\
\text { cavities (3) }\end{array}$ & in fabrication & $\begin{array}{l}\text { HOM dampers, } \\
\text { HV supplies }\end{array}$ \\
\cline { 1 - 2 } $\begin{array}{l}\text { wire scanners (8) } \\
\text { rings, H+V }\end{array}$ & $\begin{array}{l}\text { prototype tests in } \\
\text { PSB }\end{array}$ & $\begin{array}{l}\text { design + } \\
\text { fabrication }\end{array}$ \\
\cline { 1 - 2 } $\begin{array}{l}\text { fast blade profile } \\
\text { monitor in PSB }\end{array}$ & $\begin{array}{l}\text { prototype being } \\
\text { designed }\end{array}$ & $\begin{array}{l}\text { design and } \\
\text { fabrication }\end{array}$ \\
\cline { 1 - 2 }
\end{tabular}

Table 3: Status of major hardware systems, TRIUMF contributions.

\section{STATUS OF THE “PS FOR LHC” PROJECT}

The project of converting the PS complex for the LHC was launched in 1994 and will be finished by 2000. Right from the start, a fruitful collaboration with TRIUMF has been established, formalised in 1996 by a CERNTRIUMF cooperation agreement on the LHC. About one quarter of the funds and manpower required are being furnished by TRIUMF (Table 3 ).

In summary, the aim of the project is to deliver routinely to the SPS a beam of nominal characteristics (81 bunches, each $10^{11} \mathrm{p}, \varepsilon *<3.0 \mu \mathrm{m}, \varepsilon_{\mathrm{L}} \sim 0.35 \mathrm{eVs}$ ), and possibly more intensity, by 1999 . Presently everything indicates that this goal will be met. This will enable the SPS to assess, in time, its upgrading scheme.

\section{ACKNOWLEDGEMENTS}

The excellent collaboration with the colleagues at TRIUMF and the timely provision of resources are instrumental in the good progress of the "PS Conversion for LHC" project. The authors are particularly indebted to the TRIUMF coordinator, E. Blackmore, as well as to M.J. Barnes, G. Clark, M. Craddock, D. Dale, F. Jones, R. Keitel, S. Koscielniak, F. Mammarella, A.K. Mitra, A. Otter, R.L. Poirier, P. Reeve, K. Reiniger, G.D. Wait.

\section{REFERENCES}

[1] The LHC Study Group, The Large Hadron Collider, Conceptual Design, CERN/AC/95-05 (LHC).

[2] L. Evans, LHC status and plans, this conference.

[3] P. Collier (editor), The SPS as injector for LHC, conceptual design, CERN-SL-97-07, March 1997.

[4] G. Clark, A. Otter, P. Reeve, Magnets for the CERN PS Booster transfer line, this conference.

[5] G.D. Wait, M.J. Barnes (TRIUMF), K.D. Metzmacher, L. Sermeus (CERN), The application of saturating inductors for improving the performance of the CERN PS kicker systems, this conference.

[6] R. Garoby, D. Grier, E. Jensen (CERN), A.K. Mitra, R.L. Poirier (TRIUMF), The PS $40 \mathrm{MHz}$ bunching cavity, this conference.

[7] The PS staff, reported by K. Schindl, Partial test of the PS complex as LHC proton injector, Proc. $4^{\text {th }}$ EPAC, London 1994, p. 500.

[8] K. Schindl, The PS Booster as pre-injector for LHC, Proc. $3^{\text {rd }}$ Int. Workshop on High Brightness Beams for Large Hadron Colliders ("LHC96"), Montreux, Switzerland, Oct. 1996, to be published in Part. Acc.

[9] R. Cappi, The PS in the LHC injector chain, LHC96, Montreux, Switzerland, Oct. 1996, to be published in Particle Accelerators.

[10] B. Autin, L. Giulicchi, A. Jansson, M. Lindroos, A. Lombardi, M. Martini, K. Schindl, Automated emittance preservation in the PS complex, this conference.

[11] R. Garoby, Longitudinal limitations in the PS complex for the generation of the LHC proton beam, LHC96, Montreux, Switzerland, Oct. 1996, to be published in Particle Accelerators. 